\title{
Anti-Inflammatory Activities of an Extract of In Vitro Grown Adventitious Shoots of Toona sinensis in LPS-Treated RAW264.7 and Propionibacterium acnes-Treated HaCaT Cells
}

\author{
Hyeon-Ji Lim ${ }^{1,+}$, In-Sun Park ${ }^{1,+}$, Eun Yee Jie ${ }^{2}$, Woo Seok Ahn ${ }^{2}$, Sang-Jun Kim ${ }^{1}$, \\ Seung-Il Jeong ${ }^{1}{ }^{(\mathbb{C}}$, Kang-Yeol Yu ${ }^{1}$, Suk Weon Kim ${ }^{2, *}{ }^{\mathbb{1}}$ and Chan-Hun Jung ${ }^{1, *}$ \\ 1 Jeonju AgroBio-Materials Institute, Jeonju-si, Jeollabuk-do 54810, Korea; lhj0923@jami.re.kr (H.-J.L.); \\ witwit58@jami.re.kr (I.-S.P.); process95@jami.re.kr (S.-J.K.); sijeong@jami.re.kr (S.-I.J.); \\ kangyu@jami.re.kr (K.-Y.Y.) \\ 2 Biological Resource Center, Korea Research Institute of Bioscience \& Biotechnology, Jeongeup-si, \\ Jeollabuk-do 56212, Korea; jeannie@kribb.re.kr (E.Y.J.); dntjr0412@kribb.re.kr (W.S.A.) \\ * $\quad$ Correspondence: kimsw@kribb.re.kr (S.W.K.); biohun@gmail.com (C.-H.J.); Tel.: +82-63-560-5650 (S.W.K.); \\ $+82-63-711-1026$ (C.-H.J.) \\ + These authors contributed equally to this study.
}

Received: 29 October 2020; Accepted: 1 December 2020; Published: 3 December 2020

check for updates

\begin{abstract}
Toona sinensis has been traditionally used to treat dysentery, enteritis, flatulence, and itchiness. However, the existence of anti-inflammatory effects of T. sinensis on Propionibacterium acnes-induced skin disease is unknown. In vitro cultures of plant cells and tissues produced under controlled conditions offer a continuous production platform for plant natural products including pigments and anti-inflammatory agents. In this study, we determine the anti-inflammatory activities of an extract of in vitro grown adventitious shoots of $T$. sinensis on P. acnes, the etiologic agent of skin inflammation. The extract of $T$. sinensis showed antioxidant and anti-inflammatory activity in LPS-treated RAW264.7 cells. It also had antibacterial activity and anti-inflammatory effects on $P$. acnes-treated HaCaT cells. In addition, these effects were regulated by suppression of the mitogen-activated protein kinase (MAPK) pathways. These results suggesting the potential application of adventitious shoots of T. sinensis grown with an in vitro proliferation system as a medicine for treating P. acnes-induced inflammatory skin disease.
\end{abstract}

Keywords: Toona sinensis; adventitious shoots; antioxidation; antibacterial activity; anti-inflammation; P. acnes-induced inflammatory disease

\section{Introduction}

Acne is one of the most common skin diseases globally, affecting approximately 650 million adolescents and adults [1,2]. Acne is a chronic inflammatory disease which causes skin redness, itching, and inflammation [3]. Although the exact causes of acne remain unclear, environmental factors such as heredity, diet, stress, hormonal imbalance, and a narrow equilibrium between Propioninbacterium acnes (P.acnes) and other skin flora might play important roles in acne onset [4-6]. Among these factors, P. acnes, a Gram-positive anaerobic bacterium, has been reported to be a major factor in acne inflammatory reaction [7]. P. acnes may sequentially trigger toll-like receptors 2 (TLR2) and activate mitogen-activated protein kinase (MAPKs) and transcription factor nuclear factor- $\mathrm{KB}$ (NF- $\mathrm{kB}$ ) signaling pathways, leading to the production of pro-inflammatory cytokines such as interleukin (IL)-1 $\beta$, IL-6, IL-8, and tumor necrosis factor (TNF)- $\alpha$ in monocytes and keratinocytes [7-9]. In addition, enhanced expression of 
IL-8 and IL-12 due to the activation of TLR-2 can stimulate hyperkeratinization, inflammation and oxidative stress $[10,11]$.

Plant cell or tissue cultures are important tools for the genetic transformation of useful plant genotypes [12] and the continuous production of plant-derived metabolites with commercial value $[13,14]$. Plant cell or tissue cultures capable of producing useful metabolites offer a number of advantages over traditional field cultivation, including independence from geographical, seasonal, and environmental variations, uninterrupted production in uniform quality and yield, no need for pesticide or herbicide application, and comparatively short growth cycles $[15,16]$. Thus, in vitro cultures of plant cells and tissues under controlled conditions offer a continuous production platform for plant natural products including pigments and anti-inflammatory agents [17-19].

Toona sinensis (Juss.) M. Roem. (syn. Cedrela sinesis Juss.), commonly known as Chinese toon, mahogany, and cedar, belonging to family Meliaceae [20]. T. sinensis (TS), has been cultivated in Asia, including China, for a long time, and is widely used in China and Korea as traditional medicine and as a food [21]. It has various pharmacological activities, including antioxidant, anti-inflammatory, anticancer, anti-diabetic, anticoagulant, anti-gout, hepatoprotective, antibacterial, and antiviral effects [22,23]. Studies on the chemical constituents of TS have shown the presence of terpenoids, phenylpropanoids, flavonoids, and anthraquinones [24]. Among the chemical constituents of TS, terpenoids have a broad spectrum of various pharmacological functions, such as anti-inflammatory, anti-bacterial, antiviral, anticancer, and hepatoprotective activities $[25,26]$. Other chemical constituents of TS including phenylpropanoids, flavonoids, and anthraquinones also exhibit antioxidant activities [24]. However, the antibacterial and anti-inflammatory effects of TS on P. acnes-induced inflammation have not been reported to date. Therefore, the objective of this study was to evaluate the antibacterial and anti-inflammatory activities of TS extracts prepared from the dried adventitious shoots of TS and in LPS-induced RAW264.7 and P. acnes-treated HaCaT cells.

\section{Materials and Methods}

\subsection{Induction and Proliferation of Adventitious Shoots of T. sinensis}

Seeds of Toona sinensis (Juss.) M. Roem were collected from Jeongeup-si, Jeollabuk-do province, Korea in 2016 (Figure 1a,b). Seeds were sterilized in 70\% (v/v) EtOH for $0.5 \mathrm{~min}$ and soaked in 0.8\% sodium hypochlorite $(\mathrm{NaOCl})$ solution for $20 \mathrm{~min}$. After surface sterilization, seeds were rinsed thoroughly with sterilized and distilled water. To remove the remaining $\mathrm{NaOCl}$ solution, these washing processes were repeated three times. After washing, any remaining moisture was removed with sterilized filter paper (Advantec, Tokyo, Japan; $70 \mathrm{~mm}$ ). The seeds were transferred to MS [19] basal medium supplemented with $0.4 \mathrm{mg} / \mathrm{L}$ thiamine- $\mathrm{HCl}, 100 \mathrm{mg} / \mathrm{L}$ myo-inositol, $3 \%(w / v)$ sucrose, and $0.4 \%$ $(w / v)$ Gelrite. The $\mathrm{pH}$ of the medium was adjusted to 5.8 with $1 \mathrm{~N} \mathrm{NaOH}$. Cultures were maintained at $25^{\circ} \mathrm{C}$ in the dark for seed germination.
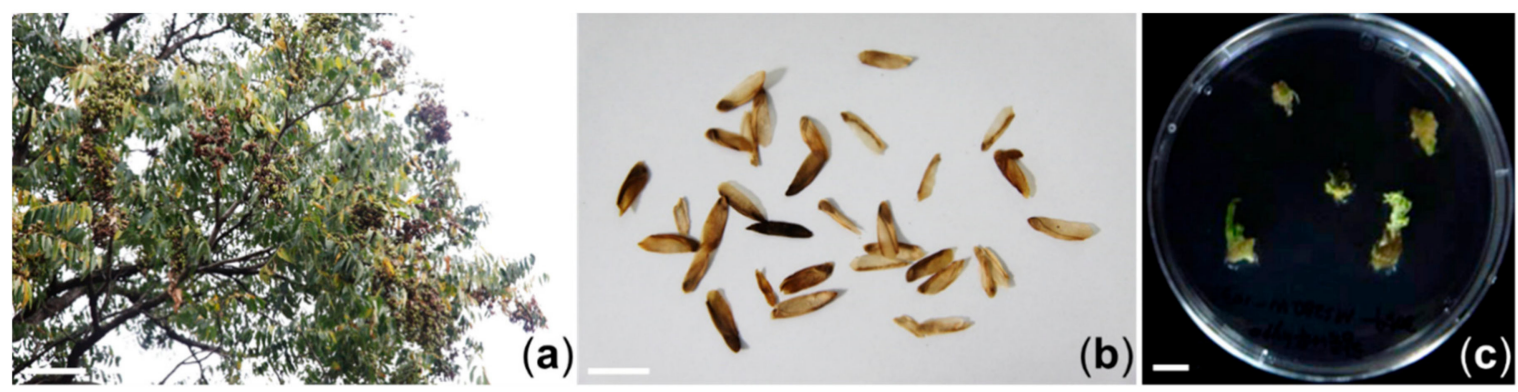

Figure 1. Establishment of an in vitro proliferation system from hypocotyl explants of T. sinensis: (a) Field grown plant of T. sinensis; (b) Mature seeds of T. sinensis; (c) In vitro grown adventitious shoots of T. sinensis. Scale bar, $1 \mathrm{~m}$ in $(\mathbf{a})$ and $1 \mathrm{~cm}$ in $(\mathbf{b}, \mathbf{c})$. 
To induce adventitious shoots, hypocotyl explants from two week-old seedlings were collected and cut into small segments (approximately $5 \mathrm{~mm}$ in length). Hypocotyl explants were place onto MS medium supplemented with $2 \mathrm{mg} / \mathrm{L}$ BA (benzyl aminopurine), $0.1 \mathrm{mg} / \mathrm{L}$ NAA ( $\alpha$-naphthaleneacetic acid), $0.4 \mathrm{mg} / \mathrm{L}$ thiamine- $\mathrm{HCl}, 100 \mathrm{mg} / \mathrm{L}$ myo-inositol, $3 \%(w / v)$ sucrose, and $0.4 \%(w / v)$ Gelrite (MS2B01N). Each treatment of ten explants had three replicates. All cultures were maintained at $25^{\circ} \mathrm{C}$ with light (approximately $30 \mu \mathrm{mol} / \mathrm{m}^{2} \mathrm{~s}$, light/dark regime of $16 / 8 \mathrm{~h}$ ) unless otherwise mentioned.

\subsection{Preparation of TS Extract}

After four weeks of incubation, rapidly growing adventitious shoots derived from hypocotyl explants of T. sinensis were transferred to fresh MS2B01N medium and incubated at $25^{\circ} \mathrm{C}$ with light for four weeks. After four weeks of incubation, rapidly growing adventitious shoots were collected, freeze-dried, ground into a fine powder, dissolved in dimethyl sulfoxide (DMSO), and sonicated for $1 \mathrm{~h}$. After centrifugation at 12,000 rpm for $5 \mathrm{~min}$, the supernatant (TS extract) was used for this study.

\subsection{DPPH Scavenging Activity Assay}

DPPH (1,1-diphenyl-2-picrylhydrazyl) scavenging activity assay was performed as described previously [19]. In brief, $100 \mu \mathrm{L}$ of the TS extract at different concentrations (50, 100, 250, and $500 \mu \mathrm{g} / \mathrm{mL}$ ) was mixed with $100 \mu \mathrm{L}$ of freshly prepared $0.1 \mathrm{mM} \mathrm{DPPH}$ in ethanol and incubated at $37^{\circ} \mathrm{C}$ in the dark for $30 \mathrm{~min}$. The absorbance of the mixture was measured at $517 \mathrm{~nm}$ with a microplate reader (Thermo Scientific, Waltham, MA, USA). The percentage inhibition of DPPH radical scavenging activity was calculated with the following formula:

DPPH scavenging activity $(\%)=1-($ Absorbance of control Absorbance of sample)/Absorbance of control $\times 100 \%$

\subsection{Superoxide Dismutase (SOD) Activity Assay}

A superoxide dismutase (SOD) activity assay was performed using an SOD assay kit (Sigma Aldrich, St. Louis, MO, USA). In brief, $20 \mu \mathrm{L}$ of the TS extract at different concentrations (50, 100, 250, and $500 \mu \mathrm{g} / \mathrm{mL}$ ) was mixed with $220 \mu \mathrm{L}$ of the reaction mixture in the SOD kit and incubated at $37{ }^{\circ} \mathrm{C}$ for $20 \mathrm{~min}$. The absorbance of the mixture was measured at $450 \mathrm{~nm}$ with a microplate reader (Thermo Scientific, Waltham, MA, USA). The SOD activity (percentage of inhibition of WST-1 reduction) was determined with the following formula:

$$
\begin{aligned}
& \text { SOD inhibition activity }(\%)=1-(\text { Absorbance of control - } \\
& \text { Absorbance of sample)/Absorbance of control } \times 100 \%
\end{aligned}
$$

\subsection{Cell Cultures}

Murine macrophage cell line RAW264.7 was purchased from Korean Cell Line Bank (Seoul, Korea). Human keratinocyte cell line HaCaT was purchased from CLS Cell Lines Service (Eppelheim, Germany). RAW264.7 and HaCaT cells were cultured in DMEM (WELGENE, Seoul, Korea) supplemented with $10 \%$ fetal bovine serum (Hyclone, Logan, UT, USA) and incubated at $37^{\circ} \mathrm{C}$ in an incubator with $5 \% \mathrm{CO}_{2}$.

\subsection{Antibacterial Assay}

Antibacterial activity was determined using an agar disc diffusion method. P. acnes was purchased from the American Type Culture Collection (Manassas, VA, USA) and cultured with Brain Heart Infusion (BHI) agar (BD Biosciences, San Jose, CA, USA) in anaerobic condition at $37^{\circ} \mathrm{C}$. Sterile filter paper discs $(8 \mathrm{~mm}$ ) were treated with 1, 2, and $3 \mathrm{mg} /$ disc of TS extract or DMSO and placed on BHI agar plate spread with $P$. acnes. Clear zones of growth inhibition around discs were measured after $48 \mathrm{~h}$ of incubation at $37^{\circ} \mathrm{C}$. 


\subsection{Cell Viability Assay}

RAW264.7 cells and HaCaT cells seeded into 96-well plates at a density of $5 \times 10^{3}$ cells/well and incubated at $37^{\circ} \mathrm{C}$ for $24 \mathrm{~h}$. The cultured cells were then treated with various concentrations (50, 100, 250, and $500 \mu \mathrm{g} / \mathrm{mL}$ ) of TS extract for $24 \mathrm{~h}$. After adding $5 \mathrm{mg} / \mathrm{mL}$ of MTT reagent (Sigma Aldrich, St. Louis, MO, USA) to each well, cells were incubated for $4 \mathrm{~h}$. The supernatant was removed and the formazan crystal in each well was solubilized with $100 \mu \mathrm{L}$ DMSO. The absorbance was then measured at $570 \mathrm{~nm}$ with a microplate reader (Thermo Scientific, Waltham, MA, USA).

\subsection{Measurement of $N O$ and $P G E_{2}$}

RAW264.7 cells were seeded into 24 -well plates at a density of $5 \times 10^{4}$ cell/well. These cells were pretreated with various concentrations $(50,100,250$, and $500 \mu \mathrm{g} / \mathrm{mL}$ ) of TS extract for $1 \mathrm{~h}$. Cells were then treated with $1 \mu \mathrm{g} / \mathrm{mL}$ of LPS. After $24 \mathrm{~h}$, the supernatant in each well was collected for nitric oxide (NO) and $\mathrm{PGE}_{2}$ determination. Concentrations of $\mathrm{NO}$ and $\mathrm{PGE}_{2}$ in supernatants were measured with Griess Reagent (Promega, Madison, WI, USA) and ELISA kits (R\&D Systems, Minneapolis, MN, USA) according to each manufacturer's instructions.

\subsection{Enzyme-Linked Immunosorbent Assay (ELISA)}

RAW264.7 cells were seeded into 24 -well plates at a density of $5 \times 10^{4}$ cell/well. These cells were pretreated with various concentrations $(50,100,250$, and $500 \mu \mathrm{g} / \mathrm{mL}$ ) of TS extract for $1 \mathrm{~h}$. Cells were then treated with $1 \mu \mathrm{g} / \mathrm{mL}$ of LPS. After $24 \mathrm{~h}$, the supernatant was collected from each well for ELISA mouse IL-6 cytokine (BD Biosciences).

$\mathrm{HaCaT}$ cells were seeded into 24 -well plates at a density of $5 \times 10^{4}$ cell/well. Cells were then pretreated with various concentrations $(50,100,250$, and $500 \mu \mathrm{g} / \mathrm{mL}$ ) of TS extract for $4 \mathrm{~h}$. After that, they were treated with $P$. acnes for $18 \mathrm{~h}$. The supernatant was then collected from each well for ELISA measurement of IL-6 and IL-8 cytokines (BD Biosciences). In Brief, 96-well plates were coated with $100 \mu \mathrm{L}$ of capture antibodies and incubated overnight at $4{ }^{\circ} \mathrm{C}$. Plates were then washed three times with washing buffer (0.05\% Tween in PBS) and blocked with an assay diluent (10\% FBS in PBS) at room temperature for $1 \mathrm{~h}$. After the medium was aspirated, $100 \mu \mathrm{L}$ of each standard or sample was added to each well for $2 \mathrm{~h}$. Plates were then washed again and $100 \mu \mathrm{L}$ of detection antibody solution was added to each well for $2 \mathrm{~h}$. Accordingly, $100 \mu \mathrm{L}$ of TMB substrate solution was added to each well and incubated at room temperature for $30 \mathrm{~min}$ in the dark. The absorbance was measured at $450 \mathrm{~nm}$ with a microplate reader (Thermo Scientific, Waltham, MA, USA).

\subsection{Real-Time RT-PCR}

Total RNA was extracted using RNA extraction kit (GeneAll, Seoul, Korea) according to the manufacturer's protocols. Total RNA was reversed-transcribed to cDNA with cDNA synthesis Kit (BioFACT, Seoul, Korea). Real-time RT-PCR was performed using SYBR Green qPCR Master Mix (BioFACT, Seoul, Korea) and a Real-time PCR system (Bio-Rad, Hercules, CA, USA). Primer sequences are shown in Table 1. Relative amounts of mRNAs were calculated based on the threshold cycle number using $\beta$-actin as an endogenous control. All experiments were performed in triplicate and values were averaged. 
Table 1. Primer sequences used for real-time PCR.

\begin{tabular}{ccc}
\hline \multicolumn{2}{c}{ Gene } & Sequence (5' $^{\prime}$ to $\mathbf{3}^{\prime}$ ) \\
\hline COX-2 & Forward & CTCTACAACAACTCCATCCT \\
(mouse) & Reverse & ATTCTGCAGCCATTTCCTTC \\
iNOS & Forward & CGAAACGCTTCACTTCCAA \\
(mouse) & Reverse & TGAGCCTATATTGCTGTGGCT \\
$\beta$-actin & Forward & CGGTTCCGATGCCCTGAGGCTCTT \\
(mouse) & Reverse & CGTCACACTTCATGATGGAATTGA \\
IL-6 & Forward & AGCCACTCACCTCTTCAGAAC \\
(human) & Reverse & GCCTCTTTGCTGCTTTCACAC \\
IL-8 & Forward & CTGATTTCTGCAGCTCTGTG \\
(human) & Reverse & GGGTGGAAAGGTTTGGAGTATG \\
GAPDH & Forward & TGCACCACCAACTGCTTAGC \\
(human) & Reverse & GGCATGGACTGTGGTCATGAG \\
\hline
\end{tabular}

\subsection{Western Blot Analyses}

RAW264.7 and HaCaT cells were seeded into six-well plates at a density of $5 \times 10^{5}$ cell/well. These cells were pretreated with various concentrations (50,100, 250, and $500 \mu \mathrm{g} / \mathrm{mL}$ ) of TS extract for $2 \mathrm{~h}$ and then treated with LPS $(1 \mu \mathrm{g} / \mathrm{mL})$ for $24 \mathrm{~h}$ or P. acnes for $2 \mathrm{~h}$. RAW264.7 cells were harvested with PBS and lysed using lysis buffer (Thermo Scientific, Waltham, MA, USA) for $1 \mathrm{~h}$. Proteins in cell lysates were separated by $10 \%$ sodium dodecyl sulfate (SDS)-polyacrylamide gel electrophoresis (SDS-PAGE) and then transferred to PVDF membranes (Merck, Darmstadt, Germany). Membranes were blocked with $5 \%$ BSA for $2 \mathrm{~h}$ and incubated at $4{ }^{\circ} \mathrm{C}$ overnight with primary antibodies: anti-iNOS, anti-COX-2, anti-p38, antiphospho-p38, antiphospho-ERK, antiphospho-JNK, and anti- $\beta$-actin antibodies from Cell Signaling Technology (Danver, MA, USA), and anti-ERK, anti-JNK, and anti-GAPDH from Santa Cruz Biotechnology (Santa Cruz, CA, USA). Blots were washed with TBST (Tris-buffered saline, $0.1 \%$ Tween 20) for $1 \mathrm{~h}$ and incubated with secondary antibodies for $30 \mathrm{~min}$. Protein bands were detected using ECL western blotting detection reagents (GE healthcare, Buckinghamshire, UK) and an Amersham Imager 600 (GE healthcare, Buckinghamshire, UK).

\subsection{Statistical Analysis}

All experiments were repeated at least three times. Statistical significance was determined using Student's $t$-test or one-way analysis of variance (GraphPad Software, La Jolla, CA, USA).

\section{Results and Discussion}

\subsection{In Vitro Proliferation of Adventitious Shoots of T. sinensis}

Adventitious shoots were successfully induced from hypocotyl explants of T. sinensis when they were cultured on MS2B01N medium after four weeks of incubation. These shoots were transferred to fresh MS2B01N medium and subcultured at four-week intervals (Figure 1c). After subculture, proliferated calluses were collected carefully and freeze-dried to determine antioxidant, tyrosinase inhibition, and antibacterial activities. A HPLC-DAD analysis was performed on a methanol extract to confirm the quality of this plant material (Supplementary Materials Figure S1).

\subsection{Anntioxidant Effects of TS Extract}

T. sinensis is known to have antibacterial and anti-inflammatory activities, and commonly used as a natural herbal medicine for treating dysentery, enteritis, and itchiness [3]. However, the anti-inflammatory effects of TS on P. acnes-induced inflammation disease remain unknown. To investigate the bioactivities of TS on P. acnes-induced inflammation, we first prepared a TS extract from dried adventitious shoots of TS. As acne lesions are known to be associated with high reactive oxygen species (ROS) [27,28], we performed DPPH and SOD assays to measure the antioxidant activity 
of TS extract. Ascorbic acid was used as a positive control (Supplementary Materials Figure S2). Figure 2a shows the DPPH radical scavenging activity of TS extract in a dose-dependent manner. As shown in Figure $2 \mathrm{~b}$, the antioxidant effect was confirmed using an SOD assay. The $\mathrm{IC}_{50}$ values were $177.1 \pm 5.18 \mu \mathrm{g} / \mathrm{mL}$ for TS extract and $5.0 \pm 0.26 \mu \mathrm{g} / \mathrm{mL}$ for ascorbic acid in the DPPH methods, and $56.5 \pm 2.97 \mu \mathrm{g} / \mathrm{mL}$ and $14.3 \pm 0.22 \mu \mathrm{g} / \mathrm{mL}$ in the SOD assay, respectively. This finding indicated that the TS extract possessed significant antioxidant activity.

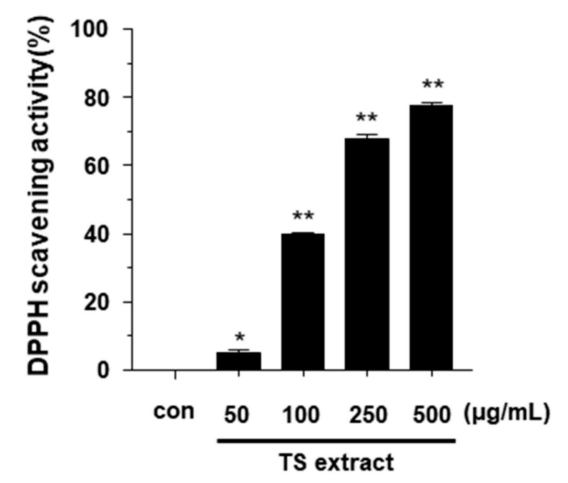

(a)

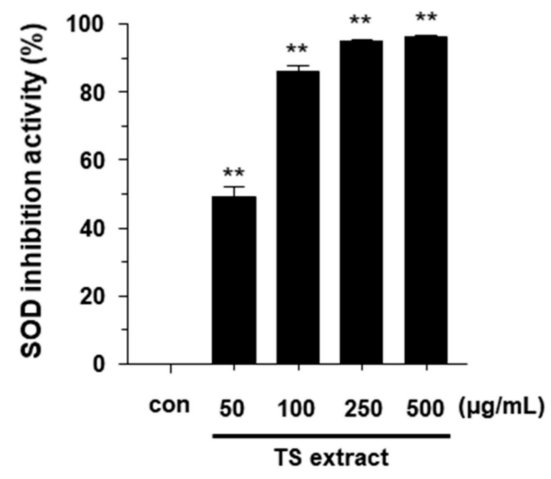

(b)

Figure 2. Antioxidant activity of TS extract. (a) DPPH scavenging activity of TS extract (50, 100, 250, and $500 \mu \mathrm{g} / \mathrm{mL}$ ) was measured by DPPH assay; (b) SOD inhibition activity of TS extract (50, 100, 250, and $500 \mu \mathrm{g} / \mathrm{mL}$ ) was determined by SOD assay kit. Ascorbic acid was used as a positive control. Values are expressed as mean \pm SD of three independent experiments. ${ }^{*} p<0.05$; ${ }^{* *} p<0.001$ vs. the control.

\subsection{Cytotoxicity and Anti-inflammatiory Effects of TS Extract on RAW264.7 Cells}

The cytotoxicity of TS extract to RAW264.7 cells was analyzed by exposing cells to various concentrations $(50,100,250$, and $500 \mu \mathrm{g} / \mathrm{mL}$ ) of the extract for $24 \mathrm{~h}$. As shown in Figure 3a, the TS extract did not show any significant cytotoxic effects compared to the control. To test the anti-inflammatory effects of the TS extract under a noncytotoxic condition, the inhibitory activity of the extract against LPS-induced NO production in RAW264.7 cells was first investigated. A nitric oxide synthesis inhibitor, L-NMMA, was used as a positive control (Supplementary Materials Figure S3). As shown in Figure 3b, the TS extract significantly decreased LPS-induced NO production. The TS extract and L-NMMA exhibited NO inhibitory activities with $\mathrm{IC}_{50}$ values of $400.37 \pm 3.72 \mu \mathrm{g} / \mathrm{mL}$ and $83.42 \pm 2.67 \mu \mathrm{M}$, respectively (Figure $3 \mathrm{~b}$ and Figure S3). Next, to confirm anti-inflammatory effects of the TS extract, the inhibitory activity of the extract against LPS-induced $\mathrm{PGE}_{2}$ production in RAW264.7 cells was investigated. RAW264.7 cells were pretreated with TS extract at various concentrations $(0,50$, 100,250 , and $500 \mu \mathrm{g} / \mathrm{mL}$ ) for $1 \mathrm{~h}$ and then treated with $1 \mu \mathrm{g} / \mathrm{mL}$ of LPS for $24 \mathrm{~h}$. Levels of $\mathrm{PGE}_{2}$ in culture supernatants were determined with Griess assay and an ELISA kit. As shown in Figure 3c, the TS extract significantly reduced levels of $\mathrm{PGE}_{2}$ in LPS-treated RAW274.7 cells in a dose-dependent manner. These results indicate that TS extract has anti-inflammatory effects by inhibiting NO and $\mathrm{PGE}_{2}$ production. It has been reported that $\mathrm{NO}$ and $\mathrm{PGE}_{2}$ are synthesized by iNOS and COX-2 in inflammatory reactions [29]. Therefore, the question of whether the inhibitory effects of the TS extract on $\mathrm{NO}$ and $\mathrm{PGE}_{2}$ production were related to the regulation of expression of their synthesis enzymes iNOS and COX-2, respectively, was investigated. As shown in Figure 3d, the TS extract significantly reduced protein levels of iNOS and COX-2 in LPS-treated RAW264.7 cells in a dose-dependent manner. We also measured the mRNA levels of iNOS and COX-2 by real-time PCR. The results showed that the TS extract significantly inhibited the mRNA levels of COX-2 and iNOS in a dose-dependent manner (Figure 3e,f). Moreover, the TS extract significantly reduced the secretion of IL-6 in LPS-treated RAW264.7 cells (Supplementary Materials Figure S4). These results suggest that TS extract can reduce $\mathrm{NO}$ and $\mathrm{PGE}_{2}$ production by suppressing the mRNA levels of iNOS and COX-2. 


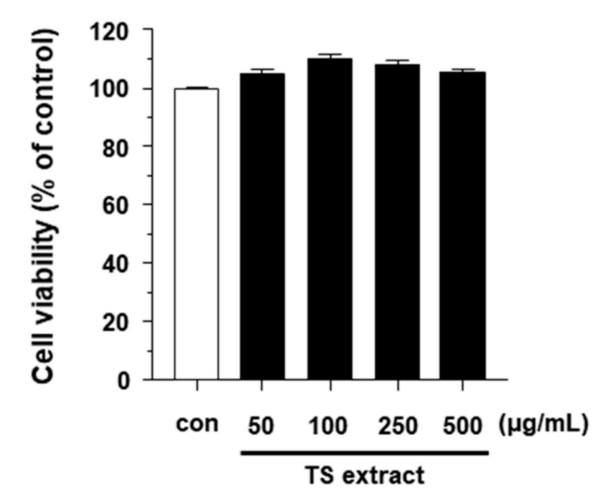

(a)

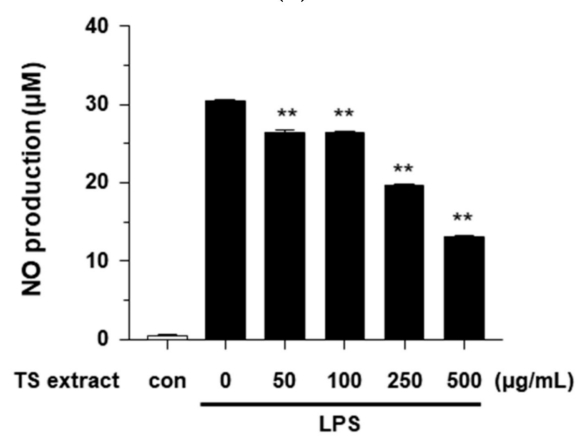

(b)

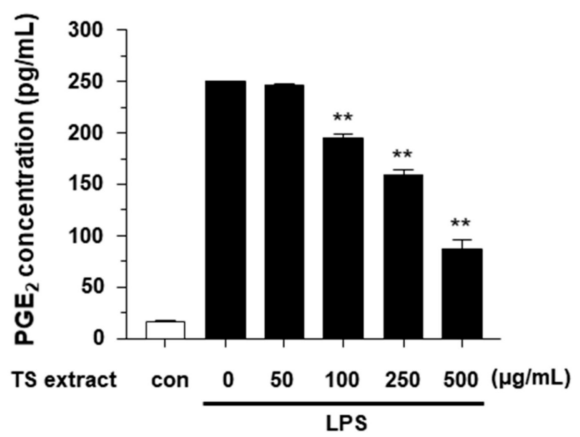

(c)

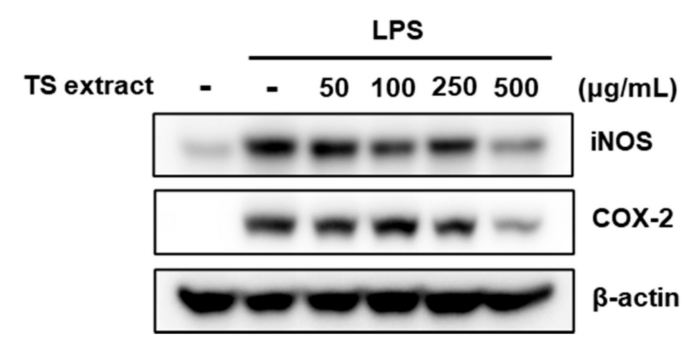

(d)

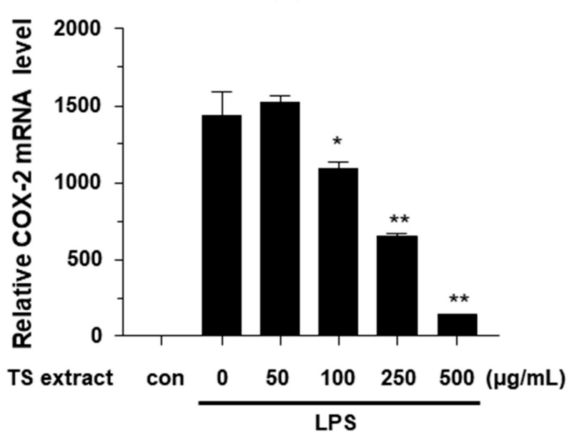

(e)

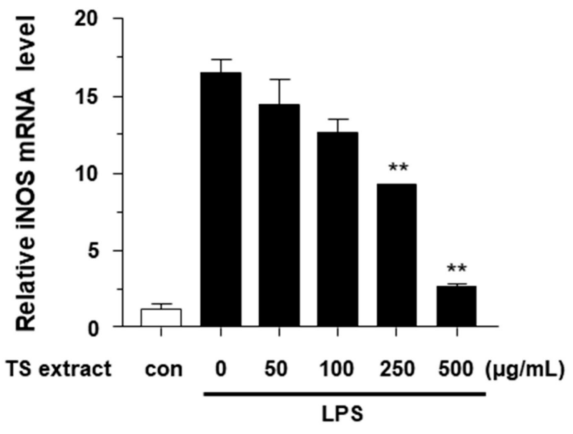

(f)

Figure 3. Anti-inflammatory effects of TS extract in LPS-treated RAW264.7 cells. (a) Cells were treated without or with the indicated concentration of TS extract and cell viability was determined by MTT assay; (b) Cells were pretreated with indicated concentration of TS extract for $1 \mathrm{~h}$ and then incubated with $1 \mathrm{ug} / \mathrm{mL}$ of LPS for $24 \mathrm{~h}$. The level of nitrite (NO) was detected using a Griess reaction assay; (c) The level of $\mathrm{PGE}_{2}$ was determined using ELISA kit; (d) Protein levels of COX-2 and iNOS were determined by western blot; (e,f) Relative mRNA levels of COX-2 and iNOS were determined by real-time PCR. Values are expressed as mean \pm SD of three independent experiments; ${ }^{*} p<0.05$; ** $p<0.001$ vs. LPS alone.

\subsection{Antibacterial Activity of TS Extract Against P. acnes}

Inflammatory response, including the pro-inflammatory mediators (iNOS and COX-2) and cytokines (IL-1 $\beta$, IL-6, and IL-8), is associated with inflammatory skin diseases such as acne [7-9,30]. The TS extract showed anti-inflammatory effects by suppressing the pro-inflammatory mediators (iNOS and COX-2) and cytokine (IL-6) production in LPS-treated RAW264.7 cells (Figure 3 and Figure S4). To determine the antibacterial activity of TS extract against $P$. acnes, agar disc diffusion assay was performed using DMSO as a negative control. As shown in Figure 4, a TS extract at concentrations 
of $2 \mathrm{mg} /$ disc and $3 \mathrm{mg} /$ disc resulted in clear zones of $1 \mathrm{~mm}$ and $1.4 \mathrm{~mm}$ in diameter, respectively. However, a lower concentration $(1 \mathrm{mg} /$ disc) of TS extract had no antibacterial activity against $P$. acnes. This finding indicates that TS extract could inhibit the growth of $P$. acnes at concentrations of $2 \mathrm{mg} /$ disc or higher.

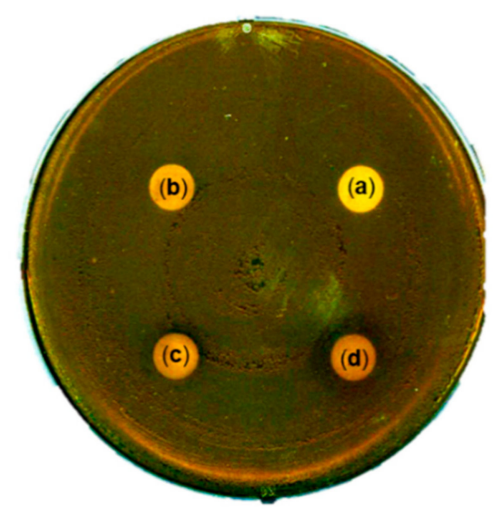

Figure 4. Antibacterial activity of TS extract. (a) DMSO; (b) $1 \mathrm{mg} /$ disc of TS extract; (c) $2 \mathrm{mg} / \mathrm{disc}$ of TS extract; (d) $3 \mathrm{mg} /$ disc of TS extract.

\subsection{Anti-Inflammatory Effects of TS Extract in P. acnes-treated HaCaT Cells}

The cytotoxicity of the TS extract to HaCaT cells was analyzed by exposing cells to various concentrations $(50,100,250$, and $500 \mu \mathrm{g} / \mathrm{mL}$ ) of the extract. As shown in Figure 5a, the TS extract did not show any cytotoxic effect. To determine the anti-inflammatory effects of the TS extract against $P$. acnes-treated $\mathrm{HaCaT}$ cells, the inhibitory activities on $P$. acnes-induced inflammatory cytokine secretion in $\mathrm{HaCaT}$ cells were investigated. $\mathrm{HaCaT}$ cells were pretreated with various concentrations $(0,50,100,250$, and $500 \mu \mathrm{g} / \mathrm{mL})$ of TS extract for $4 \mathrm{~h}$, and then treated with P. acnes for $18 \mathrm{~h}$. As shown in Figure $5 b, c$, the TS extract significantly suppressed the secretion of IL-6 and IL-8 in HaCaT cells. We also determined the mRNA levels of IL-6 and IL-8 in P. acnes-treated HaCaT cells. The results showed that the TS extract significantly inhibited the mRNA levels of IL- 6 and IL- 8 in a dose-dependent manner (Figure $5 \mathrm{~d}, \mathrm{e}$ ). These results suggest that TS extract can inhibit the production of pro-cytokines IL-6 and IL-8 by reducing their mRNA levels in P. acnes-treated HaCaT cells.

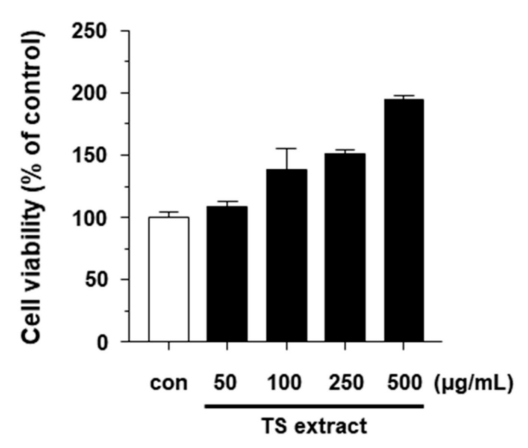

(a)

Figure 5. Cont. 


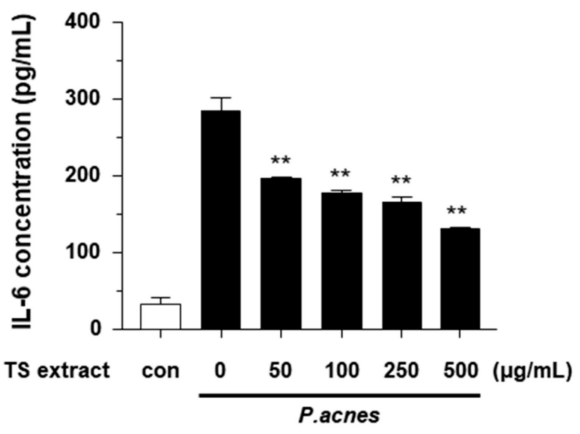

(b)

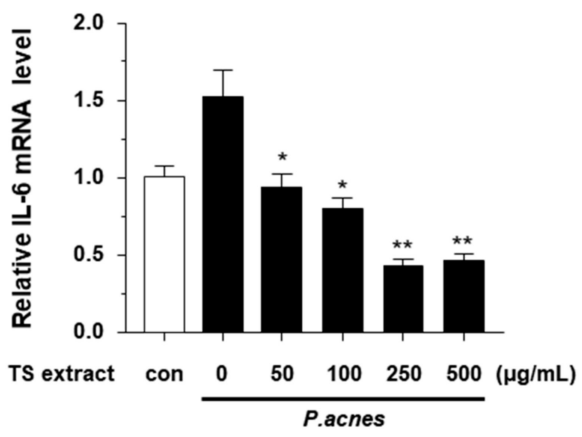

(d)

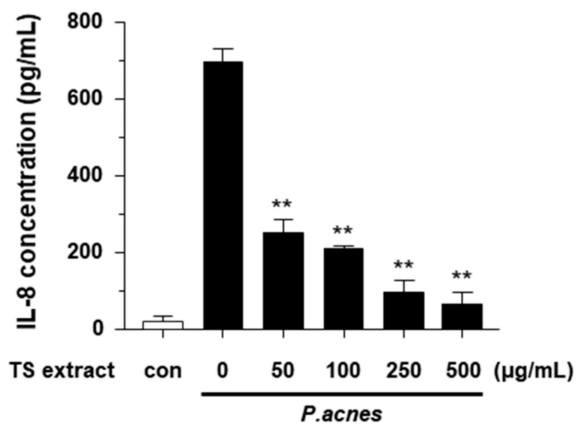

(c)

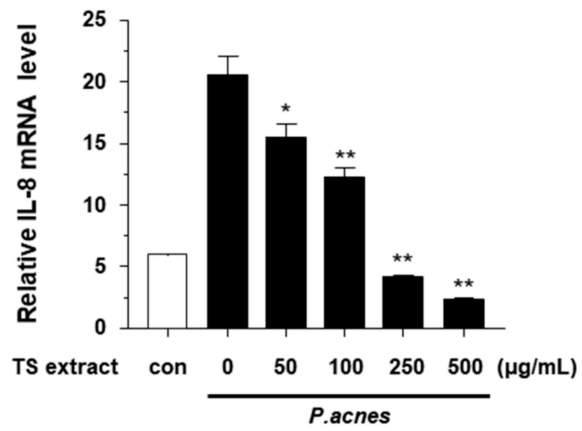

(e)

Figure 5. Anti-inflammatory effects of TS extract in P. acnes-treated HaCaT cells. (a) Cells were treated without or with indicated concentrations of TS extract and cell viability was determined by MTT assay; (b) Cells were pretreated with indicated concentrations of TS extract for $4 \mathrm{~h}$ and then treated with P. acnes for $18 \mathrm{~h}$. Secretion level of IL-6 was determined by ELISA kit; (c) Secretion level of IL-8 was determined by ELISA kit; (d,e) Relative mRNA levels of IL- 6 and IL- 8 were determined by real-time PCR. Values are expressed as mean \pm SD of three independent experiments; ${ }^{*} p<0.05 ;{ }^{* *} p<0.001$ vs. P. acnes alone.

\subsection{Regulatory Effects of TS Extract on Activated MAPK Signaling Pathway in P. acnes-Treated HaCaT Cells}

It has been reported that $P$. acnes can induce inflammatory response via the MAPK signaling pathway [7-9]. Therefore, the question of whether the anti-inflammatory effects of the TS extract were regulated by the MAPK signaling pathway was investigated. As shown in Figure 6, the expression levels of phosphorylated $\mathrm{p} 38$, JNK, and ERK following treatment of P. acnes were increased. However, the expression levels of phosphorylated p38, JNK, and ERK decreased significantly by treatment with the TS extract. These results suggest that TS extract can inhibit $P$. acnes-induced inflammatory response by regulation of the MAPK signaling pathway in HaCaT cells.

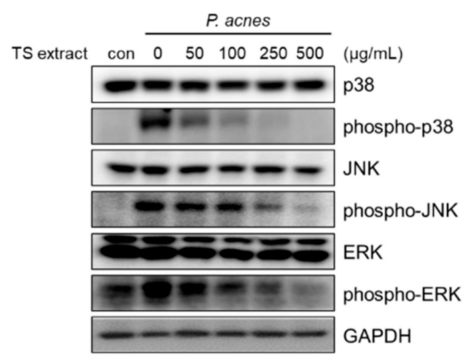

Figure 6. Effect of TS extract on the MAPK signaling pathway in P. acnes-treated HaCaT cells. Cells were pretreated with indicated concentrations of TS extract for $2 \mathrm{~h}$ and then treated with P. acnes for $2 \mathrm{~h}$. The levels of p38, phospho-p38, JNK, phospho-JNK, ERK, and phospho-ERK were compared by Western blotting. GAPDH was used as a loading control. 


\section{Conclusions}

We established an in vitro proliferation system for adventitious shoots of $T$. sinensis and demonstrated that a TS extract had antibacterial and anti-inflammatory activities against P. acnes-induced inflammation by inhibiting the release of pro-inflammatory cytokines via suppression of MAPK signaling pathways. These findings suggest that a TS extract might have applications as a medicine for treating P. acnes-induced inflammatory diseases. However, since these effects were observed at high concentrations, further in vitro and in vivo percutaneous absorption studies are required for applications to treat $P$. acnes-induced inflammatory diseases.

Supplementary Materials: The following are available online at http://www.mdpi.com/2223-7747/9/12/1701/s1, Figure S1: HPLC chromatograms of in vitro grown adventitious shoots of T. sinensis., Figure S2: Antioxidant activity of ascorbic acid., Figure S3: Anti-inflammatory effects of NG-nitro-L-arginine methyester (L-NMME) in LPS-treated RAW264.7 cells., Figure S4: Anti-inflammatory effects of TS extract in LPS-treated RAW264.7 cells.

Author Contributions: Conceptualization, H.-J.L., I.-S.P., K.-Y.Y., and C.-H.J.; methodology, H.-J.L., I.-S.P., E.Y.J., W.S.A., S.-J.K., and C.-H.J.; software, H.-J.L., I.-S.P., and C.-H.J.; validation, H.-J.L. and I.-S.P.; formal analysis, H.-J.L., I.-S.P., and C.-H.J.; investigation, H.-J.L., I.-S.P., E.Y.J., W.S.A., and S.-J.K.; resources, H.-J.L., I.-S.P., E.Y.J., S.W.K., and C.-H.J; data curation, H.-J.L., I.-S.P., and C.-H.J.; writing-original draft preparation, H.-J.L. and C.-H.J.; writing-review and editing, S.W.K. and C.-H.J.; visualization, H.-J.L., I.-S.P., S.-J.K., and C.-H.J.; supervision, S.-I.J., K.-Y.Y., S.W.K., and C.-H.J.; project administration, S.W.K., and C.-H.J.; funding acquisition, S.-I.J., and S.W.K. All authors have read and agreed to the published version of the manuscript.

Funding: This work was supported by the National Research Foundation of Korea grant funded by the Korea government (MSIT) (2020R1H1A1100615) and the Jeonju AgroBio-Material Institute (JAMI). This work was also supported by a grant of the Korea Health Technology R\&D Project through the Korea Health Industry Development Institute (KHIDI) funded by the Ministry of Health \& Welfare, Republic of Korea (HP20C0231).

Conflicts of Interest: The authors declare no conflict of interest.

\section{References}

1. Tan, J.K.; Bhate, K. A global perspective on the epidemiology of acne. Br. J. Dermatol. 2015, 172, 3-12. [CrossRef]

2. Vos, T.; Flaxman, A.D.; Naghavi, M.; Lozano, R.; Michaud, C.; Ezzati, M.; Shibuya, K.; Salomon, J.A.; Abdalla, S.; Aboyans, V.; et al. Years lived with disability (YLDs) for 1160 sequelae of 289 diseases and injuries 1990-2010: A systematic analysis for the Global Burden of Disease Study 2010. Lancet 2012, 380, 2163-2196. [CrossRef]

3. Zhu, X.; Mao, Y.; Guo, M.; Yu, H.; Hao, L.; Hua, Q.; Lu, Z.; Hong, M.; An, F. Enhancement of anti-acne effect of Scutellaria baicalensis extract by fermentation with symbiotic fungus Penicillium decumbens. J. Biosci. Bioeng. 2020, 130, 457-463. [CrossRef] [PubMed]

4. $\quad$ Dong, Y.M.; Liao, L.Y.; Li, L.; Yi, F.; Meng, H.; He, Y.F.; Guo, M.M. Skin inflammation induced by ambient particulate matter in China. Sci. Total Environ. 2019, 682, 364-373. [CrossRef]

5. Wolkenstein, P.; Machovcová, A.; Szepietowski, J.C.; Tennstedt, D.; Veraldi, S.; Delarue, A. Acne prevalence and associations with lifestyle: A cross-sectional online survey of adolescents/young adults in 7 European countries. J. Eur. Acad. Dermatol. Venereol. 2018, 32, 298-306. [CrossRef]

6. Melnik, B.C. Linking diet to acne metabolomics, inflammation, and comedogenesis: An update. Clin. Cosmet. Investig. Dermatol. 2015, 8, 371-388. [CrossRef] [PubMed]

7. Jugeau, S.; Tenaud, I.; Knol, A.C.; Jarrousse, V.; Quereux, G.; Khammari, A.; Dreno, B. Induction of toll-like receptors by Propionibacterium acnes. Br. J. Dermatol. 2005, 153, 1105-1113. [CrossRef] [PubMed]

8. Vowels, B.R.; Yang, S.; Leyden, J.J. Induction of proinflammatory cytokines by a soluble factor of Propionibacterium acnes: Implications for chronic inflammatory acne. Infect. Immun. 1995, 63, 3158-3165. [CrossRef] [PubMed]

9. Huang, W.C.; Tsai, T.H.; Chuang, L.T.; Li, Y.Y.; Zouboulis, C.C.; Tsai, P.J. Anti-bacterial and anti-inflammatory properties of capric acid against Propionibacterium acnes: A comparative study with lauric acid. J. Dermatol. Sci. 2014, 73, 232-240. [CrossRef] [PubMed]

10. Dessinioti, C.; Katsambas, A. Propionibacterium acnes and antimicrobial resistance in acne. Clin. Dermatol. 2017, 35, 163-167. [CrossRef] 
11. Sinha, P.; Srivastava, S.; Mishra, N.; Yadav, N.P. New perspectives on antiacne plant drugs: Contribution to modern therapeutics. Biomed. Res. Int. 2014, 2014, 301304. [CrossRef] [PubMed]

12. Altpeter, F.; Springer, N.M.; Bartley, L.E.; Blechl, A.E.; Brutnell, T.P.; Citovsky, V.; Conrad, L.; Gelvin, S.B.; Jackson, D.; Kausch, A.P.; et al. Advancing crop transformation in the era of genome editing. Plant Cell. 2016, 28, 1510-1520. [CrossRef]

13. Verpoorte, R.; van der Heijden, R.; Memelink, J. Engineering the plant cell factory for secondary metabolite production. Transgen. Res. 2000, 9, 323-343. [CrossRef]

14. Debnath, M.; Malik, C.P.; Bisen, P.S. Micropropagation: A tool for the production of high quality plant-based medicines. Curr. Pharm. Biotechnol. 2006, 7, 33-49. [CrossRef] [PubMed]

15. Rao, S.R.; Ravishankar, G.A. Plant cell cultures: Chemical factories of secundary metabolites. Biotechnol. Adv. 2002, 20, 101-153. [PubMed]

16. Fischer, R.; Vasilev, N.; Twyman, R.M.; Schillberg, S. High-value products from plants: The challenges of process optimization. Curr. Opin. Biotechnol. 2015, 32, 156-162. [CrossRef] [PubMed]

17. Ochoa-Villarreal, M.; Howat, S.; Hong, S.; Jang, M.O.; Jin, Y.W.; Lee, E.K.; Loake, G.J. Plant cell culture strategies for the production of natural products. BMB Rep. 2016, 49, 149-158. [CrossRef]

18. Espinosa-Leal, C.A.; Puente-Garza, C.A.; García-Lara, S. In vitro plant tissue culture: Means for production of biological active compounds. Planta 2018, 248, 1-18. [CrossRef]

19. Murashige, T.; Skoog, F.A. A revised medium for rapid growth and bioassays with tobacco tissue cultures. Physiol. Plant. 1962, 15, 473-497. [CrossRef]

20. Liao, J.W.; Yeh, J.Y.; Lin, Y.C.; Wei, M.M.; Chung, Y.C. Mutagenicity and safety evaluation of water extract of fermented Toona sinensis Roemor leaves. J. Food Sci. 2009, 74, T7-T13. [CrossRef]

21. Truong, V.L.; Ko, S.Y.; Jun, M.; Jeong, W.S. Quercitrin from Toona sinensis (Juss.) M.Roem. Attenuates Acetaminophen-Induced Acute Liver Toxicity in HepG2 Cells and Mice through Induction of Antioxidant Machinery and Inhibition of Inflammation. Nutrients 2016, 8, 431. [CrossRef] [PubMed]

22. Cheng, K.W.; Yang, R.Y.; Tsou, S.C.; Lo, C.S.; Ho, C.T.; Lee, T.C.; Wang, M. Analysis of antioxidant activity and antioxidant constituents of Chinese toon. J. Funct. Foods. 2009, 1, 253-259. [CrossRef]

23. Wu, C.C.; Liu, C.H.; Chang, Y.P.; Hsieh, S.L. Effects of hot-water extract of Toona sinensis on immune response and resistance to Aeromonas hydrophila in Oreochromis mossambicus. Fish Shellfish Immunol. 2010, 29, 258-263. [CrossRef]

24. Peng, W.; Liu, Y.; Hu, M.; Zhang, M.; Yang, J.; Liang, F.; Huang, Q.; Wu, C. Toona sinensis: A comprehensive review on its traditional usages, phytochemisty, pharmacology and toxicology. Rev. Bras. Farmacogn. 2019, 29, 111-124. [CrossRef] [PubMed]

25. James, J.T.; Dubery, I.A. Pentacyclic triterpenoids from the medicinal herb, Centella asiatica (L.) Urban. Molecules 2009, 14, 3922-3941. [CrossRef]

26. Zhou, M.; Zhang, R.H.; Wang, M.; Xu, G.B.; Liao, S.G. Prodrugs of triterpenoids and their derivatives. Eur. J. Med. Chem. 2017, 131, 222-236. [CrossRef] [PubMed]

27. Gyamfi, M.A.; Yonamine, M.; Aniya, Y. Free-radical scavenging action of medicinal herbs from Ghana: Thonningia sanguinea on experimentally-induced liver injuries. Gen. Pharmacol. 1999, 32, 661-667. [CrossRef]

28. Grange, P.A.; Chéreau, C.; Raingeaud, J.; Nicco, C.; Weill, B.; Dupin, N.; Batteux, F. Production of superoxide anions by keratinocytes initiates P. acnes-induced inflammation of the skin. PLoS Pathog. 2009, 5, e1000527. [CrossRef]

29. Hussein, S.Z.; Mohd Yusoff, K.; Makpol, S.; Mohd Yusof, Y.A. Gelam honey attenuates carrageenan-induced rat paw inflammation via NF-kB pathway. PLoS ONE 2013, 8, e72365. [CrossRef]

30. Bhat, Y.J.; Latief, I.; Hassan, I. Update on etiopathogenesis and treatment of Acne. Ind. J. Dermatol. Venereol. Leprol. 2017, 83, 298-306. [CrossRef]

Publisher's Note: MDPI stays neutral with regard to jurisdictional claims in published maps and institutional affiliations. 